\title{
The Black-backed Three-toed Woodpecker
}

by David Stirling, Victoria, B.C.

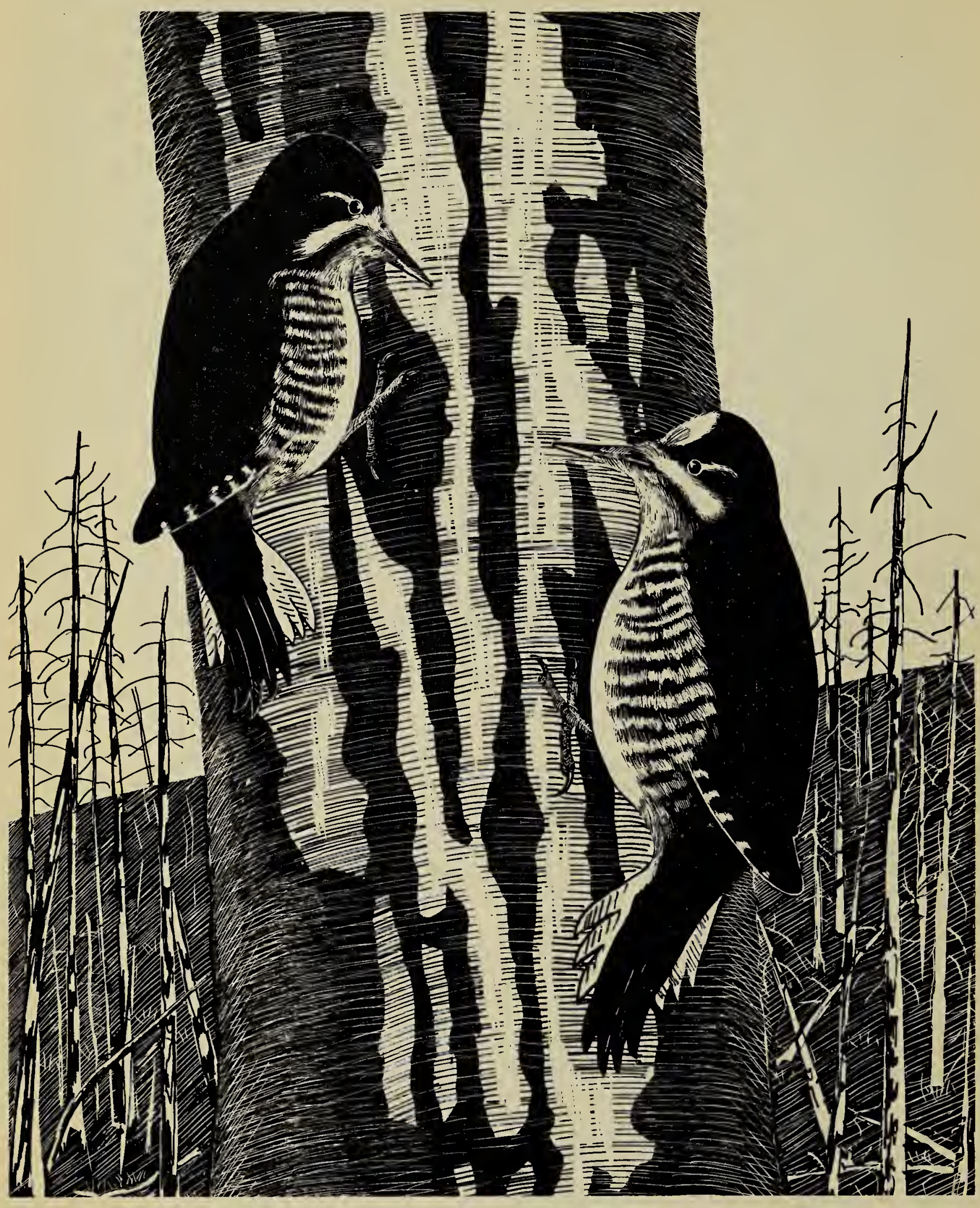

Drawing by Raymond Barnes, Victoria

A pair of Black-backed Three-toed Woodpeckers at work on a charred snag.

Black-backed Three-toed Woodpecker (Picoides arcticus) is the tongue twister name of this rather scarce resident of the northern foresits across the continent. Only after a spring fire kills a tract of standing timber do three-toed woodpeckers appear in considerable numbers. The reason for this increase is the everexpanding food supply in the form of bark beetles and engraving beetles. These insects have attacked both dead and injured trees after the fire and as a result of the increased food 
supply a population explosion occurs. Millions of larvae tunnel into the cambium layers of these trees, and many fire-distressed trees that normally would recover are killed because of the heavy beetle infestation.

The presence of three-tored woodpeckers is indicated by infested trees that have been almoist stripped of bark. Sometimes a bird will spend days or even weeks working on a single tree. Often isolated "beetle trees" are nearly denuded of bark by one of these woodpeckers. It is possible that this bird is an important factor in limiting outbreaks of treedestroying inseats of the families Scolytidae and Buprestidae.

Early last spring, when in the Cariboo, I walked through a blackened region which had been swept by fire the previous year. Everywhere I saw the signs where ithree-toed woodpeckers had been working during the winter. Presently I heard a sharp "pic-pic-pic" and saw a flash of yellow. A.male bird on a charred Douglas fir had turned his head showing his colourful crown patch.

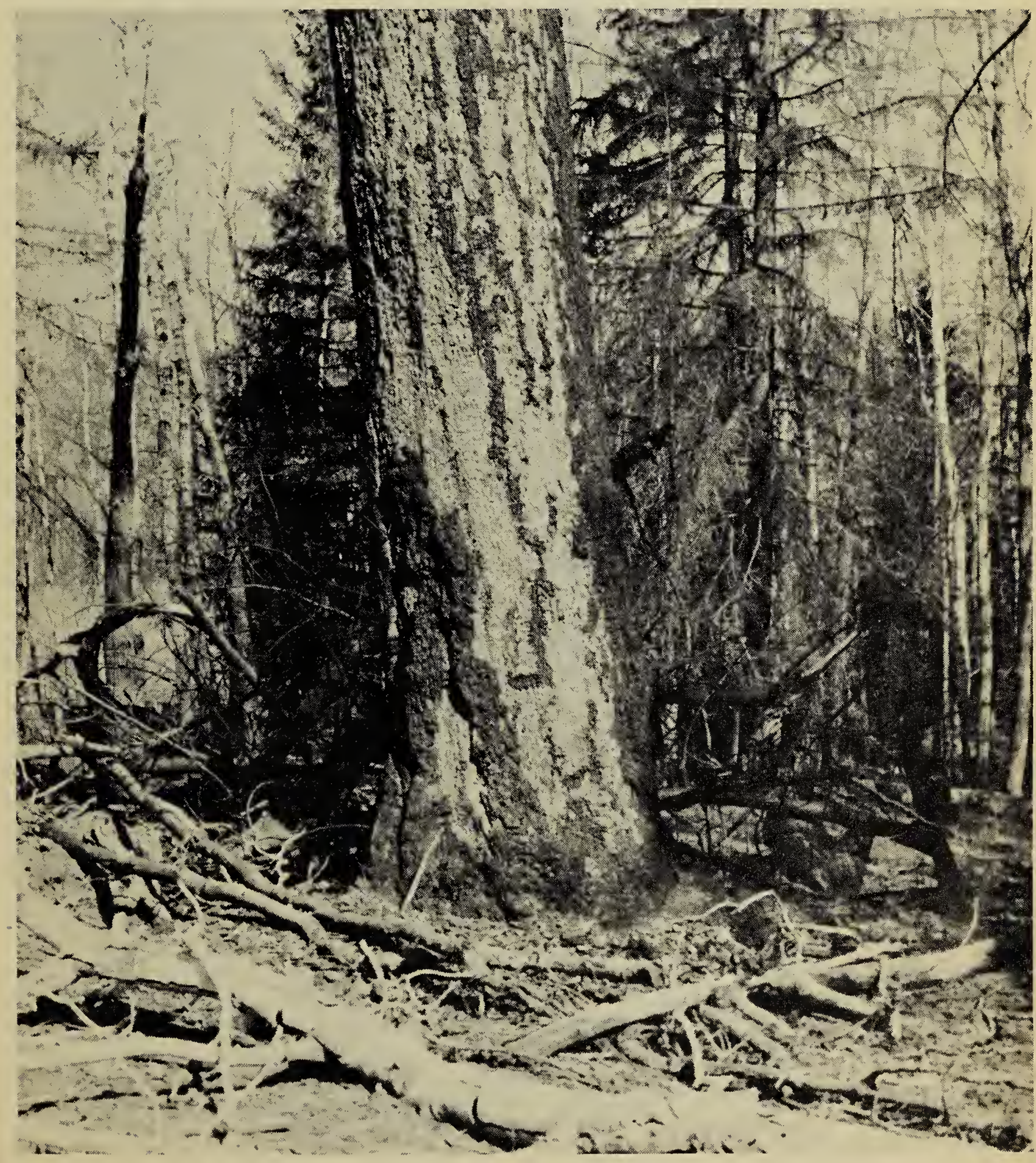

Photo by D. Stirling

A well-worked Douglas fir. In this instance only the outer layer of the heavy bark has been chipped off. 